\title{
Ernst's ego
}

\section{Max Ernst delved into his childhood experiences to find images for his art that would both explore Freudian psychology and mock those who put unquestioning faith in scientific rationality.}

\section{Martin Kemp}

T he charting of the darkly mysterious labyrinths of the unconscious mind in early twentieth-century psychology, above all by Freud, seemed at once to promise a new science of human nature and to threaten the intellectual structures of other institutionalized sciences as the true models of knowledge and as the secure foundations of modern life. The double-edged nature of the psychological sword was explored more profoundly by Max Ernst than by any other artist of his era.

Educated at the University of Bonn in Germany in 1909-12, Ernst was introduced to the experimental psychology of Wilhelm Wundt and his followers. Throughout his life, the artist's grasp of contemporary psychology extended far beyond the bowdlerized Freudian formulas favoured by many of his Surrealist colleagues.

The prime vehicle Ernst exploited to evoke the mélanges of memory images and the symbolic fantasies of dream states was the collage. He cannibalized, juxtaposed and overlaid images garnered voraciously from a wide range of general and specialist publications to paint the enigmatic landscapes of his inner mind. The popular science periodical, La Nature, was a favourite source.

\section{The resulting juxtapositions may appear irrational yet Ernst's method was avowedly "experimental". "Collage is a hypersensitive and rigorously exact instrument, a seismograph capable of registering the exact potentialities of human welfare in every epoch," he wrote.}

In series of collages from the early 1930s, pictures within pictures are "presented" by Loplop, the semi-mythical bird of his childhood, a pet cockatoo that had died at the moment of his sister's birth. This "oiseau supérieur" appears as a sinister caricature above the central image, and stands as his "alter ego", into which he displaces himself as a "third" person. Ernst was undoubtedly aware of Freud's A Childhood Memory of Leonardo da Vinci, which centred on Leonardo's infant memory of his mouth being touched by a bird's tail. Freud illustrated the 1919 edition with Oskar Pfister's fantastical diagram of a vulture concealed in the skirts of St Anne in Leonardo's painting in the Louvre.

Ernst's Facility, also, Loplop Presents combines images cut from an anatomical atlas with marbled paper and a blotter with scribbled sums, set against a drawn background.

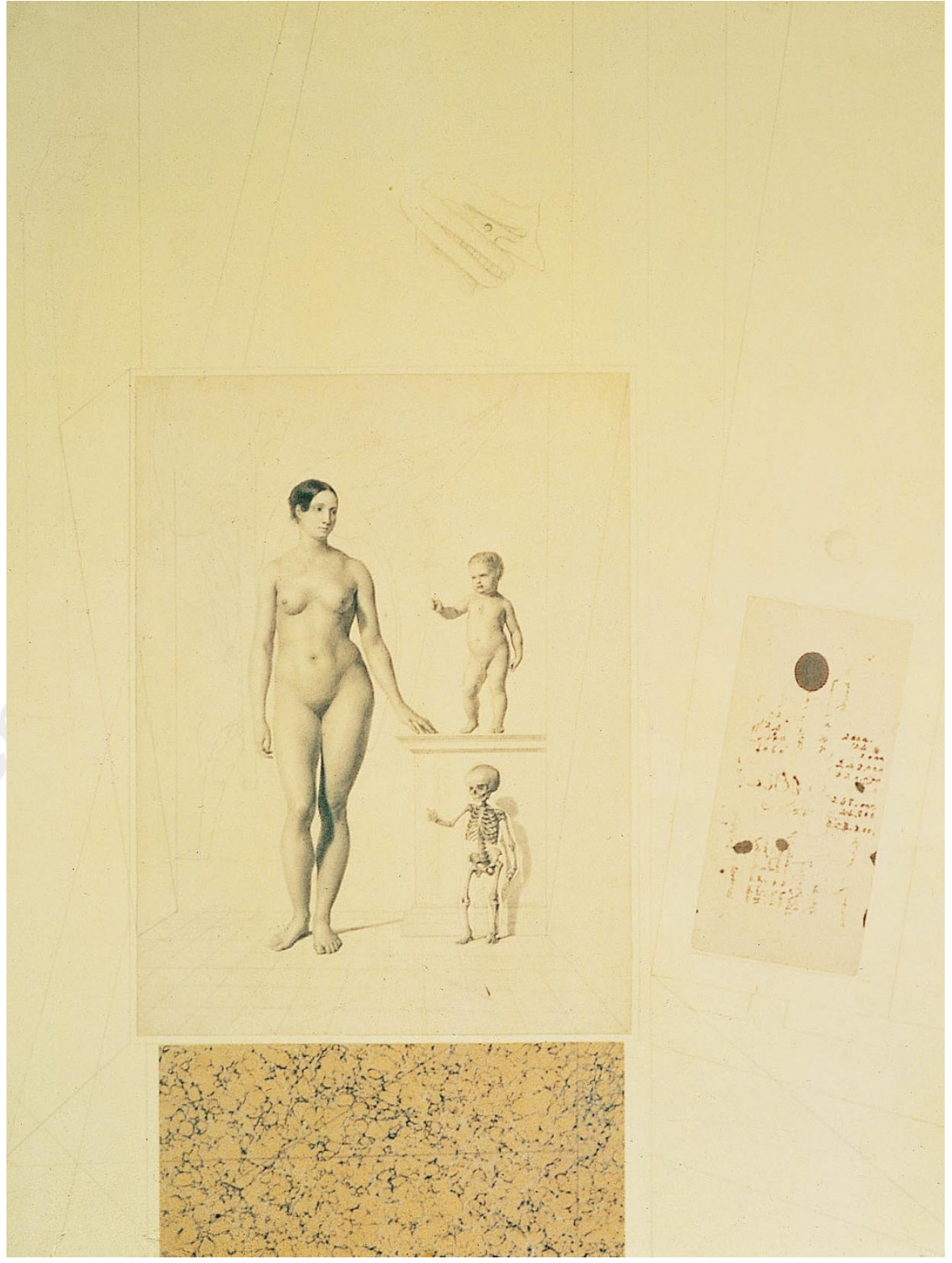

Ernst's Facility, also, Loplop Presents, collage and pencil, 1931, private collection, London.

The space of the inner picture is systematically laid out in geometrical perspective - a reference to facile academic naturalism - while the ground occupied by Loplop's disembodied head offers no such coherence. The pedestrian 'science of art' as a mirror of scientific rationality is mocked by the leering bird.

Specialized scientific imagery often seemed in Ernst's eyes to be oddly mocking of its own claims. Ernst found that "anatomical or physical demonstrations... united such mutually distant physical elements that the very absurdity of the array called forth in us a hallucinating succession of contradictory images, superimposed on one another with the persistence and rapidity of remembered lovemaking".

From Ernst's perspective, modern sciences and technologies, with their array of weird visual images, were manifestations of the strange obsessions of our psyche, and were seen as subject to the "uncertainty principle" that bedevils all acts of human observation and representation.

Martin Kemp is in the Department of the History of Art, University of Oxford, 35 Beaumont Street, Oxford OX12PG, UK 